\title{
PEMANFAATAN BUAH BERENUK (Crescentia cujete Linn) SEBAGAI BAHAN BAKU PEMBUATAN BIOETANOL
}

\author{
Bahroni dan Istianah \\ Program Studi Kimia, Fakultas Sains dan Teknologi, UIN Syarif Hidayatullah Jakarta \\ bahroni.uinjkt@gmail.com
}

\begin{abstract}
ABSTRAK
Bahan bakar minyak yang berasal dari fosil tergolong sebagai bahan bakar yang tidak terbarukan sehingga jika diproduksi secara terus-menerus akan mengakibatkan habisnya cadangan minyak bumi. Solusi untuk menghadapi persoalan tersebut adalah dengan mencari sumber bahan bakar lain yang tergolong sebagai bahan bakar terbarukan, salah satunya adalah bioetanol. Bioetanol merupakan senyawa yang dapat dihasilkan dari proses fermentasi tumbuhan yang mengandung gula sederhana atau pati dan selulosa dengan perlakuan tertentu. Sejauh ini, pengembangan bioetanol masih mengalami berbagai macam kendala, di antaranya yaitu masih sering terjadi kompetisi sumber bahan baku antara pembuatan bioetanol dan pangan sehingga berdampak terhadap ketersediaan pangan di Indonesia. Berenuk (Crescentia cujete Linn) merupakan buah yang berpotensi sebagai bahan baku pembuatan bioetanol dimana ketersediaannya melimpah namun kurang dimanfaatkan oleh masyarakat. Penelitian ini bertujuan untuk mengetahui pengaruh penambahan ragi Saccharomyces cerevisiae terhadap kadar bioetanol yang dihasilkan dari daging buah berenuk. Daging buah berenuk dihaluskan kemudian dibagi menjadi tiga variabel, yaitu $\mathrm{A}, \mathrm{B}$ dan $\mathrm{C}$ dengan variasi penambahan ragi sebanyak 5, 7 dan 9 gram. Fermentasi dilakukan selama tiga hari kemudian destilasi sebanyak dua kali, yaitu pada suhu 95 dan $78-85{ }^{\circ} \mathrm{C}$. Hasil pengukuran dengan alkohol meter pada destilasi pertama menunjukkan kadar etanol sebesar 12\%, 15\% dan 16\%, sedangkan pengukuran menggunakan metode Piknometer pada hasil destilasi ke- 2 menunjukkan kadar etanol sebesar 35\%, 55\% dan 70\% pada sampel A, B dan C dengan volume destilat 17,5, 14 dan 11,5 mL secara berturut-turut.
\end{abstract}

Kata Kunci: Berenuk, Bioetanol

\section{PENDAHULUAN}

Bahan bakar minyak yang berasal dari fosil tergolong sebagai bahan bakar yang tidak terbarukan (unrenewable fuels), sehingga jika diproduksi secara terusmenerus dapat mengakibatkan habisnya cadangan minyak bumi. Di sisi lain, pertumbuhan penduduk secara tidak langsung menyebabkan peningkatan permintaan terhadap bahan bakar minyak.
Untuk menghadapi masalah di atas, maka perlu dicari sumber alternatif lain. Salah satu di antaranya yaitu bioetanol yang dapat diproduksi secara berkelanjutan karena bahan bakunya tersedia secara alami dan dapat diperbaharui. Bahan bakar tersebut secara umum disebut sebagai bahan bakar terbarukan (renewable fuels).

Bioetanol adalah etanol yang bahan utamanya berasal dari tumbuhan dan 
diproses dengan cara fermentasi. Etanol atau etil alkohol $\left(\mathrm{C}_{2} \mathrm{H}_{5} \mathrm{OH}\right)$ berupa cairan bening dan terurai secara biologis (biodegradable) (Rikana, 2005). Meskipun memiliki berbagai keuntungan, produksi bioetanol juga dapat menimbulkan masalah. Bahan baku pembuatan bioetanol seperti tebu, jagung, dan singkong merupakan tanaman yang banyak dimanfaatkan oleh masyarakat sebagai bahan pangan. Jika lahan tanaman pangan tersebut dialihkan menjadi lahan produksi bioetanol, maka produksi pangan akan menurun. Di sisi lain, molase (tetes tebu) yang merupakan limbah pembuatan gula pasir sudah sering digunakan untuk sintesis bioetanol, namun hal ini berarti produksi bioetanol akan bergantung pada produksi gula dimana jika produksi gula menurun maka produksi bioetanol juga akan menurun seiring dengan menurunnya ketersediaan molase sebagai bahan utamanya. Dalam penelitian ini dilakukan pembuatan bioetanol menggunakan bahan baku generasi pertama namun bukan sebagai sumber bahan pangan, yaitu buah berenuk (Crescentia cujete Linn).

\section{Crescentia cujete Linn (dalam} bahasa Inggris "Calabash", Prancis "Calabassier") adalah tanaman yang tumbuh pada daerah tropis, dan merupakan tanaman asli negara Amerika Tengah, Kamerun, serta beberapa negara bagian Afrika (Mahbub, 2011). Tumbuhan ini kemudian tersebar ke berbagai daerah di dunia salah satunya Indonesia dan umum dijumpai di daerah tropis. Oleh karena itu ketersediaan berenuk di Indonesia cukup melimpah, namun pemanfaatannya masih jarang dijumpai.

Tanaman ini memiliki beberapa kandungan kimia yang penting, antara lain flavonoid-quercetin (Marc, 2008), tanin, fenol, saponin, anthraquinon, dan cardenolides (Ejelonu, 2011). Buah dari tanaman berenuk ini berupa buni, bulat, ketika masih muda berwarna hijau, setelah tua berwarna coklat. Dibutuhkan sekitar enam sampai tujuh bulan untuk mematangkan dan akhirnya jatuh ke tanah. Buah ini merupakan buah musiman yang berkembang setelah penyerbukan oleh kelelawar. Buah muncul pada akhir musim kemarau dengan diameter buah sebesar 12 sampai $14 \mathrm{~cm}$ (Gilman, 1993).

\section{METODOLOGI PENELITIAN}

\section{Alat dan Bahan}

Alat yang digunakan dalam peneltian ini meliputi blender, crystallization dish, labu didih, seperangkat alat destilasi, erlenmeyer, termometer, alkohol meter, piknometer, Alumunium foil, neraca digital, dan refraktometer ABBE merk Altago tipe NAR-1T.

Bahan yang digunakan dalam penelitian ini adalah daging buah berenuk yang telah dihaluskan sebanyak 500 gram per sampel, urea 5 gram, NPK 3 gram, ragi roti (Saccharomyces cerevisiae) untuk sampel A, B dan C adalah 5, 7 dan 9 gram, $\mathrm{K}_{2} \mathrm{Cr}_{2} \mathrm{O}_{7} \%, \mathrm{H}_{2} \mathrm{SO}_{4}$ pekat, etanol $95 \%$, dan akuades.

\section{Prosedur Penelitian}

Penelitian ini dilakukan dengan metode eksperimental laboratorium dan dibagi menjadi 4 tahapan, yaitu fermentasi buah berenuk, destilasi bioetanol dari buah berenuk, uji kualitatif etanol dan pengukuran kadar alkohol.

\section{Fermentasi buah Berenuk}

Daging buah berenuk dihaluskan dengan blender, kemudian dipisahkan. Daging yang telah halus dibagi ke dalam tiga buah crystallization dish lalu ditimbang masing-masing $500 \mathrm{~g}$ dan diberi label A, B dan C. Ragi Saccharomyces cerevisiae ditambahkan ke dalam sampel A, B dan C berturut-turut sebanyak 5, 7 dan 9 gram. Untuk nutrien, digunakan pupuk urea dan NPK masing-masing sebanyak 5 dan 3 gram. Campuran diaduk hingga merata, kemudian ditutup rapat menggunakan Alumunium foil. Fermentasi dilakukan selama 3 hari dalam tempat tertutup dan gelap serta dalam kondisi anaerob. 


\section{Destilasi Bioetanol dari Buah Berenuk}

Buah berenuk yang telah difermentasi selama 3 hari disaring menggunakan kain tipis dan diambil filtratnya. Filtrat sampel A, B, dan C kemudian di destilasi sebanyak dua kali. Destilasi pertama dilakukan pada suhu 95 ${ }^{\circ} \mathrm{C}$ sedangkan destilasi kedua dilakukan pada suhu $78-85^{\circ} \mathrm{C}$.

\section{Uji Kualitatif Etanol}

\section{a. Oksidasi dengan $\mathrm{K}_{2} \mathrm{Cr}_{2} \mathrm{O}_{7}$}

Tabung reaksi disiapkan, kemudian ditambahkan $2 \mathrm{~mL} \mathrm{~K}_{2} \mathrm{Cr}_{2} \mathrm{O}_{7} 2 \%$, 5 tetes $\mathrm{H}_{2} \mathrm{SO}_{4}$ pekat dan $1 \mathrm{~mL}$ sampel. Sampel positif mengandung etanol jika warna larutan berubah dari jingga menjadi hijau.

b. Pengukuran Indeks Bias

Indeks bias diukur menggunakan Refraktometer Digital Altago tipe NAR-1T. Prisma dibilas dengan etanol kemudian indeks bias masing-masing sampel diukur.

\section{Pengukuran Kadar Alkohol}

a. Pengukuran Kadar Alkohol Destilasi Pertama dengan Alkohol Meter

Destila hasil destilasi pertama diukur sebanyak $100 \mathrm{~mL}$ dalam gelas ukur. Alkohol meter dimasukkan kedalam gelas ukur kemudian skala pada alkohol meter dibaca.

b. Pengukuran Kadar Alkohol Destilasi Kedua dengan Metode Piknometer

Pada tahap ini dilakukan penimbangan terhadap piknometer kosong, piknometer berisi aquadest, dan piknometer berisi sampel A, B dan C. Kadar alkohol dapat diketahui dengan membandingkan densitas yang diperoleh dengan data pada Tabel Farmakope.

\section{Teknik Pengumpulan dan Analisis Data}

Teknik pengumpulan data dalam penelitian ini berupa observasi atau pengamatan dalam penelitan di laboratorium. Jenis data, fakta atau informasi yang dikumpulkan dalam penelitian ini adalah data primer dan sekunder. Data primer adalah data yang berasal dari hasil eksperimen dan data sekunder berupa buku dan artikel.

Data yang diperoleh setelah destilasi berisi konsentrasi alcohol hasil pengujian menggunakan metode piknometer. Densitas sampel dapat dicari dengan formula:

$$
\text { Densitas }=\frac{\mathrm{W}_{3}-\mathrm{W}_{1}}{\mathrm{~W}_{2}-\mathrm{W}_{1}}
$$

$\mathrm{W}_{1}=$ Massa Piknometer Kosong

$\mathrm{W}_{2}=$ Massa Piknometer + Aquadest

$\mathrm{W}_{3}=$ Massa Piknometer + Sampel

Densitas yang diperoleh kemudian dibandingkan dengan Tabel Farmakope untuk mengetahui kadar Alkohol tersebut.

\section{HASIL DAN PEMBAHASAN}

\section{Fermentasi Buah Berenuk}

Proses fermentasi buah berenuk dilakukan menggunakan khamir Saccharomyces cerevisiae yang merupakan mikroorganisme unggul dalam hal fermentasi glukosa menjadi etanol. Perubahan glukosa menjadi etanol melalui jalur EMP. Adapun mekanisme yang terjadi adalah sebagai berikut:

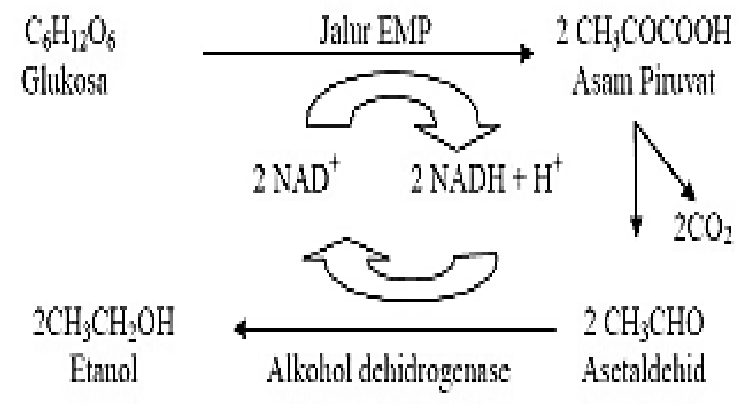

Gambar 1. Mekanisme pembentukan etanol dari proses fermentasi (Fardiaz, 1989) 
Fardiaz (1989) mengungkapkan bahwa jalur EMP terdiri dari beberapa tahap, masing-masing dikatalisis oleh enzim tertentu. Jalur tersebut ditandai dengan pembentukan fruktosa difosfat, kemudian pemecahan menjadi dua molekul gliseraldehida fosfat. Reaksi ini dikatalis oleh enzim aldolase. Kemudian terjadi reaksi dehidrogenasi gliseraldehida fosfat yang merupakan reaksi oksidasi yang menghasilkan energi dalam bentuk ATP. Reaksi ini dikatalis oleh enzim gliseraldehida fosfat dehidrogenase. Atom hidrogen yang terlepas akan ditangkap oleh NAD membentuk $\mathrm{NADH}_{2}$. Proses fermentasi dapat berlangsung terus jika $\mathrm{NADH}_{2}$ dapat dioksidasi kembali pada tahap kedua fermentasi sehingga melepaskan atom hidrogen kembali. Jadi NAD berfungsi sebagai pembawa hidrogen dalam proses fermentasi.

\section{Perbandingan Saccharomyces} cerevisiae yang digunakan adalah: sampel A sebanyak $5 \mathrm{~g}$; B sebanyak $7 \mathrm{~g}$; dan $\mathrm{C}$ sebanyak $9 \mathrm{~g}$. Tujuan dari penggunaan ragi yang berbeda pada setiap sampel adalah untuk mengetahui jumlah ragi yang efektif untuk menghasilkan bioetanol terbanyak. Selain itu ditambahkan juga pupuk urea dan NPK berturut-turut sebanyak 5 dan 3 gram. Fungsi dari pupuk urea adalah sebagai penyuplai $\mathrm{NH}_{3}$ yang merupakan sumber energi bagi mikroba sedangkan fungsi pupuk NPK banyak mengandung unsur N, dan $\mathrm{P}$ yang dibutuhkan oleh bakteri Saccharomyces cerevisiae.

Media yang digunakan yaitu gelas piala $500 \mathrm{~mL}$ yang ditutup dengan alumunium foil, lalu dilubangi beberapan kali mengunakan jarum agar $\mathrm{CO}_{2}$ yang dihasilkan dari proses fermentasi tersebut dapat keluar, sebab dengan adanya produksi gas selama proses fermentasi maka pertumbuhan Saccharomyces Cerevisiae akan berhenti meskipun masih dalam keadaan hidup, kemudian akan mulai menghasilkan alkohol kembali jika gas CO2 dihilangkan.

Selanjutnya dilakukan uji $\mathrm{pH}$ menggunakan $\mathrm{pH}$ universal karena Saccharomyces cerevisiae bertahan hidup pada pH 3-5. Hasilnya yaitu tanpa penambahan $\mathrm{H}_{2} \mathrm{SO}_{4}$, pH campuran sudah bernilai 5 . Fermentasi dilakukan selama \pm 3 hari karena jika terlalu lama dikhawatirkan terjadinya kematian Saccharomyces cerevisiae, selain itu etanol yang terkandung di dalamnya dapat berubah menjadi senyawa lain. Menurut Astuty (1991), faktor-faktor yang dapat mempengaruhi jumlah etanol yang dihasilkan dari fermentasi adalah mikroorganisme dan media yang digunakan, adanya komponen media yang dapat menghambat pertumbuhan serta kemampuan fermentasi mikroorganisme dan kondisi selama fermentasi.

\section{Destilasi Bioetanol dari Buah Berenuk}

\section{a. Destilasi Ke-1}

Destilasi ini dilakukan untuk memisahkan etanol dari air berdasarkan titik didih kedua senyawa tersebut. Suhu ideal agar etanol dapat terpisah dari air adalah pada titik didih etanol itu sendiri yaitu $\pm 78,37^{\circ} \mathrm{C}$ pada tekanan $1 \mathrm{~atm}$. Namun dikarenakan tidak ada etanol yang menetes di suhu tersebut maka suhu dinaikkan hingga mencapai $95^{\circ} \mathrm{C}$ sehingga diperoleh destilat pertama pada sampel A, B dan C berturut-turut adalah 113, 129 dan $132 \mathrm{~mL}$. Sulitnya pemisahan antara air dan etanol disebabkan oleh adanya ikatan hidrogen pada senyawa $\mathrm{H}_{2} \mathrm{O}$ dan gugus $\mathrm{OH}$ pada etanol sehingga ketika suhu dinaikkan air ikut menguap.

\section{b. Destilasi ke-2}

Destilasi ke-2 dilakukan pada suhu antara 78-85 ${ }^{\circ} \mathrm{C}$ dengan tujuan untuk memperoleh destilat dengan kadar etanol yang lebih tinggi. Hasil destilasi pada sampel A, B dan C berturut-turut adalah 17,5, 14 dan 11,5 mL. Volume destilat yang diperoleh pada destilasi ke-2 relatif sedikit. Hal ini dikarenakan karena adanya uap yang mengembun bukan di kondensor melainkan di pipa penghubung antara labu didih dan kondensor sehingga embun menetes 
kembali ke dalam cairan sampel. Selain itu ikatan hidrogen yang terjadi antara air dan etanol menyebabkan sulitnya pemisahan ini.

\section{Uji Kualitatif Etanol}

Uji Kualitatif ini ditujukkan untuk mengetahui ada atau tidaknya kandungan etanol dalam cairan destilat.

a. Oksidasi dengan $\mathrm{K}_{2} \mathrm{Cr}_{2} \mathrm{O}_{7}$

Tabel 1. Hasil uji kualitatif menggunakan senyawa $\mathrm{K}_{2} \mathrm{Cr}_{2} \mathrm{O}_{7}$

\begin{tabular}{ccc}
\hline Sampel & Suhu $\left({ }^{\circ} \mathrm{C}\right)$ & Indeks Bias \\
\hline A & 29 & 1.354 \\
B & 29 & 1.360 \\
C & 29 & 1.360 \\
\hline
\end{tabular}

Tabel 1 memperlihatkan hasil yang positif terhadap setiap sampel. Etanol merupakan senyawa alkohol primer di mana pada atom $\mathrm{C}$ yang berikatan dengan gugus $\mathrm{OH}$ mengikat 2 atom hidrogen, sehingga oksidasi dengan oksidator kuat $\mathrm{K}_{2} \mathrm{Cr}_{2} \mathrm{O}_{7}$ akan mengoksidasinya menjadi asam asetat dalam waktu relatif singkat sehingga terjadi perubahan warna $\mathrm{K}_{2} \mathrm{Cr}_{2} \mathrm{O}_{7}$ $2 \%$ dari jingga ke hijau ketika etanol diteteskan. Warna hijau tersebut berasal dari $\mathrm{Cr}^{3+}$ di mana disebabkan karena turunnya biloks $\mathrm{Cr}^{6+}$ menjadi $\mathrm{Cr}^{3+}$. $\mathrm{H}_{2} \mathrm{SO}_{4}$ berfungsi sebagai katalis untuk mempercepat reaksi tersebut. Hasil positif diketahui berdasarkan perubahan warna dari jingga menjadi hijau. Reaksi oksidasi yang terjadi adalah sebagai berikut:

$\mathrm{CH}_{3} \mathrm{CH}_{2} \mathrm{OH}+2 \mathrm{~K}_{2} \mathrm{Cr}_{2} \mathrm{O}_{7}+8 \mathrm{H}_{2} \mathrm{SO}_{4} \rightarrow$ $3 \mathrm{CH}_{3} \mathrm{COOH}+2 \mathrm{Cr}_{2}\left(\mathrm{SO}_{4}\right)_{3}+2 \mathrm{~K}_{2} \mathrm{SO}_{4}+11$ $\mathrm{H}_{2} \mathrm{O}$

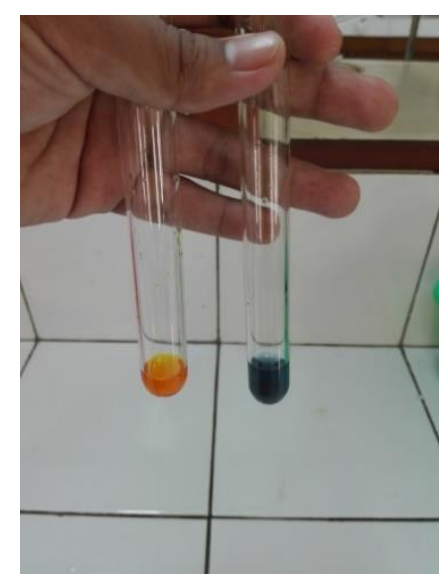

Gambar 2. Hasil uji kualitatif menggunakan $\mathrm{K}_{2} \mathrm{Cr}_{2} \mathrm{O}_{7}$

b. Pengukuran Indeks Bias

Sebelum mengukur indeks bias hasil destilasi, refraktometer dikalibrasi dengan cara mengukur indeks bias akuades. Hasilnya pada suhu $29{ }^{\circ} \mathrm{C}$ diperoleh data indeks bias air 1,332. Hasil tersebut menunjukkan bahwa refraktometer dalam keadaan terkalibrasi karena angka tersebut sesuai dengan referensi. Selanjutnya dilakukan pengukuran indeks bias terhadap etanol hasil destilasi. Suhu saat pengamatan adalah $29^{\circ} \mathrm{C}$.

Tabel 2. Hasil pengukuran indeks bias

\begin{tabular}{ccc}
\hline Sampel & $\begin{array}{c}\text { Warna } \\
\text { Akhir }\end{array}$ & Hasil Uji \\
\hline A & Hijau & $\begin{array}{c}\text { Positif } \\
(+)\end{array}$ \\
B & Hijau & $\begin{array}{c}\text { Positif } \\
(+)\end{array}$ \\
C & Hijau & $\begin{array}{c}\text { Positif } \\
(+)\end{array}$ \\
\hline
\end{tabular}

Dari tabel 2 dapat diketahui hasil pengukuran pada sampel $\mathrm{A}, \mathrm{B}$ dan $\mathrm{C}$ berturut-turut yaitu 1.354, 1.36 dan 1.36. Hasil tersebut sesuai dengan data yang ada pada Tabel Farmakope, yaitu sebagai berikut: 
Tabel 3. Tabel Farmakope

\begin{tabular}{|l|l|}
\hline \multicolumn{1}{|c|}{ Medium } & \multicolumn{1}{|c|}{ Indeks bias mutlak } \\
\hline Udara $\left(1 \mathrm{~atm}, 0^{\circ} \mathrm{C}\right)$ & 1,00029 \\
Udara $\left(1 \mathrm{~atm}, 0^{\circ} \mathrm{C}\right)$ & 1,00028 \\
Udara $\left(1 \mathrm{~atm}, 0^{\circ} \mathrm{C}\right)$ & 1,00026 \\
Air & 1,33 \\
Alkohol & 1,36 \\
Gliserin & 1,47 \\
Kaca kuarsa & 1,46 \\
Kaca kerona & 1,52 \\
Kaca flinta & 1,65 \\
Intan & 2,42 \\
\hline
\end{tabular}

Dari tabel di atas dapat disimpulkan bahwa destilat yang diperoleh merupakan senyawa alkohol (etanol).

\section{Pengukuran Kadar Alkohol}

a. Pengukuran Kadar Alkohol Destilasi Pertama dengan Alkohol Meter

Pengukuran kadar alkohol menggunakan Alkohol Meter disajikan pada tabel 4 .

Tabel 4. Hasil pengukuran kadar alkohol menggunakan Alkohol Meter

\begin{tabular}{ccc}
\hline Sampel & $\begin{array}{c}\text { Volume } \\
(\mathrm{mL})\end{array}$ & Kadar $(\%)$ \\
\hline $\mathrm{A}$ & 100 & 12 \\
$\mathrm{~B}$ & 100 & 15 \\
$\mathrm{C}$ & 100 & 16 \\
\hline
\end{tabular}

Dari tabel di atas diketahui bahwa semakin banyak ragi yang ditambahkan mengakibatkan semakin tinginya kadar alkohol (etanol). Hal ini dikarenakan oleh semakin banyaknya Saccharomyces cerevisiae yang melakukan perombakan glukosa menjadi etanol sehingga dihasilkan etanol dengan jumlah yang lebih banyak.

b. Pengukuran Kadar Alkohol Destilasi Kedua dengan Metode Piknometer

Pengujian kadar alkohol pada destilasi kedua menggunakan metode piknometer bertujuan untuk mengetahui densitas destilat yang diperoleh. Hasil perhitungan dicocokkan dengan data pada tabel Farmakope sehingga kadar etanol dapat diketahui.
Tabel 5. Hasil pengukuran kadar etanol menggunakan metode Piknometer

\begin{tabular}{|c|c|c|}
\hline Sampel & $\begin{array}{c}\text { Volume } \\
(\mathrm{mL})\end{array}$ & Kadar (\%) \\
\hline $\mathrm{A}$ & 17,5 & 35 \\
\hline $\mathrm{B}$ & 14 & 55 \\
\hline $\mathrm{C}$ & 11,5 & 70 \\
\hline
\end{tabular}

Dari data pada tabel 5, jika persen kadar dikonversi ke dalam bentuk volume maka kandungan etanol murni pada sampel A, B dan C adalah sebanyak 6,125, 7,70 dan $8,05 \mathrm{ml}$. Dari data tersebut diketahui kadar etanol tertinggi diperoleh pada sampel dengan penambahan ragi sebanyak 9 gram.

\section{PENUTUP}

\section{Kesimpulan}

Pada penelitian ini dapat disimpulkan bahwa:

1. Hasil pengukuran menggunakan alkohol meter pada destilasi pertama diperoleh destilat dengan kadar etanol sebesar $12 \%, 15 \%$ dan $16 \%$ (volume destilat 113, 129 dan $132 \mathrm{~mL}$ ), sedangkan pengukuran menggunakan metode Piknometer pada hasil destilasi ke-2 diperoleh kadar etanol sebesar 35\%, $55 \%$ dan $70 \%$ pada sampel A, B dan C dengan volume destilat 17,5, 14 dan 11,5 $\mathrm{mL}$ secara berturut-turut.

2. Kadar etanol tertinggi diperoleh pada sampel C, yaitu sampel dengan penambahan ragi sebanyak 9 gram.

\section{Saran}

Perlu dilakukan penelitian lebih lanjut dengan variasi penambahan ragi di atas 9 gram untuk mengetahui jumlah ragi yang optimum dalam menghasilkan etanol pada proses fermentasi daging buah berenuk. 


\section{DAFTAR PUSTAKA}

Astuty, E. D. 1991. Fermentasi Etanol Kulit Buah Pisang. UGM. Yogyakarta.

Ejelonu, BC., dkk. 2011. The Chemical Constituents of Calabash (Crescentia cujete). African Journal Biotechnology Vol. 10:84

Fardiaz, S. 1989. Mikrobiologi Pangan. Pusat Antar Universitas. Bogor: Institut Pertanian Bogor.

Gilman, E.F, dkk. 1993. Crescentia cujete: Calabash Tree. Florida: University of Florida
Mahbub, Khandaker Rayhan dkk. 2011. In Vitro Antibacterial Activity of Crescentia cujete and Moringa oleifera. Bangladesh Research Publication Journal Vol. 05:337-347

Marc, N.O., 2008. The Nutritive and Antinutritive Compositions of Calabash (Crescentia cujete). Journal of Food Technology 6:267-270

Rikana, H dan Adam, R. 2010. Pembuatan Bioetanol dari Singkong secara Fermentasi Menggunakan Ragi Tape. Semarang: Fakultas Teknik, Universitas Diponegoro. 